Tarbawy : Jurnal Pendidikan Islam

ISSN : 2407-4462 (Cetak), 2614-5812 (Elektronik)

Vol. 5, No. 1, 2018, Hal. 48 - 55

DOI: https://doi.org/10.32923/tarbawy.v5i1.832

\title{
Kilir Lidah Gangguan Bahasa Anak
}

\section{Vebbi Andra}

${ }^{1}$ Institut Syaikah Abdurrahman Siddik Bangka Belitung1

\begin{tabular}{ll}
\hline \hline Info Artikel: & \\
\hline Diterima & $:$ 26 Februarui 2018 \\
Direvisi & $: 15$ Maret 2018 \\
Dipublish & $: 15$ April 2018
\end{tabular}

\section{Kata Kunci:}

Kilir lidah

Bahasa

Anak

\section{Keyword :}

Tongue Twist

Language

Childhrern

\begin{abstract}
ABSTRAK
Penelitian ini merupakan penelitian kualitatif yang menggunakan metode survei. Adapun teknik pengumpulan data adalah berupa teknik simak dan teknik catat. Data dalam penelitian ini ialah berupa bahasa lisan yang digunakan oleh siswa Kelas I SD (Sekolah Dasar) Negeri 89 Kota Bengkulu yang berbentuk kesalahan berbahasa (kilir lidah asembling). Adapun teknik analisis data yang digunakan dalam penelitian ini, yaitu transkripsi, identifikasi, klasifikasi, dan kesimpulan. Hasil penelitian menunjukkan bahwa penyebab kekeliruan kilir lidah (tongue slips) asembling yang dialami oleh anak adalah dikarenakan belum sempurna atau terdapatnya kerusakan pada alat-alat bicara yang dimiliki siswa Kelas I SD (Sekolah Dasar) Negeri 89 Kota Bengkulu, dalam pikiran siswa Kelas I SD (Sekolah Dasar) Negeri 89 Kota Bengkulu belum memiliki gambaran tentang kosa kata yang baik, dan adanya pengaruh bahasa daerah terhadap penguasaan bahasa Indonesia.
\end{abstract}

This research is a qualitative study using a survey method. Like the techniques performed the data consisted of listening techniques and note taking techniques. The data in this study consisted of spoken language used by students of Class I Elementary School (SD) Negeri 89 Bengkulu City in the form of misunderstanding (asirling tongue blades). The data analysis techniques used in this study, namely transcription, collection, classification, and conclusions. The results showed that the causes of tongue slip (slip tongue) assemblies discussed by children were imperfect or involved damage to tools that talked about Class I Elementary School (SD) elementary schools in Bengkulu City, in the thinking of Class I Elementary School students (Elementary School) Negeri 89 Bengkulu City does not yet have a good picture of vocabulary, and the differences in the influence of regional languages on Indonesian language mastery.

\section{Koresponden:}

Vebbi Andra,

Email: vebbiandra@yahoo.com

This is an open access article distributed under the Creative Commons Attribution License, which permits unrestricted use, distribution, and reproduction in any medium, provided the original work is properly cited. C2019 by author.

\section{Pendahuluan}

Berbahasa adalah aktivitas sosial, di dalam berbahasa manusia harus menyadari bahwa ada kaidahkaidah yang mengatur tindakannya, penggunaan bahasanya, dan interpretasi-interpretasinya terhadap tindakan dan ucapan yang terjadi (Sari, 2014). Penguasaan terhadap bahasa merupakan salah satu keterampilan pokok yang harus dimiliki oleh setiap manusia. Kemampuan berbahasa tentu saja berfokus kepada empat aspek penting, yaitu menyimak, berbicara, membaca, dan menulis. Empat keterampilan inilah yang menjadi fokus dan target utama dalam pembelajaran bahasa (Mulyati, 2015). Agar mencapai keberhasilan dalam empat keterampilan tersebut, tentu saja pengajaran bahasa harus didukung oleh banyak faktor (Sanjaya, 2015).

Salah satu keterampilan berbahasa yang harus dikuasai dengan baik oleh anak didik (siswa) adalah kemampuan berbicara (Sumantri, 2014). Kemampuan berbicara merupakan kunci penting dalam proses sosialisasi anak terhadap lingkungannya. Pada kenyataannya, penguasaan terhadap kemampuan berbicara oleh anak khususnya di lingkungan sekolah banyak sekali mendapat hambatan (Gunarti \& Muis, 2014). Hambatan dalam proses pengajaran keterampilan berbicara bukan saja datang dari faktor eksternal, melainkan juga datang dari faktor internal anak didik itu sendiri (Sanjaya, 2015).

Faktor hambatan yang sangat sering terjadi pada anak didik atau siswa pada saat berbicara dalam proses belajar-mengajar, atau pada saat bergaul dengan sesamanya adalah disebabkan oleh kekeliruan dalam berbicara. Menurut Dardjowidjojo kekeliruan dalam bicara dapat disebabkan oleh faktor kilir lidah (Dardjowidjojo, 2003). Kekeliruan ini terjadi karena kita tidak memproduksi kata yang sebenarnya kita kehendaki. Di mana kita memproduksi kata lain, atau kita memindah-mindahkan bunyi, atau malah kita mengurutkan kata secara keliru (Andari, 2013). 
Salah satu bentuk kilir lidah yang dialami anak didik (siswa) di sekolah adalah kilir lidah (tongue slips) dalam hal asembling (Andra, 2018). Agar mendapatkan gambaran yang jelas tentang gangguan berbicara pada anak didik (siswa), untuk itu penulis akan memusatkan kajian penelitian yang berfokus pada masalah kilir lidah (tongue slips) asembling yang dialami siswa Kelas I SD (Sekolah Dasar) Negeri 89 Kota Bengkulu (Andra, 2018).

\section{Metode}

Metode yang digunakan dalam penelitian ini adalah metode survei. Metode survei ialah pengamatan atau penyelidikan yang kritis untuk mendapatkan keterangan yang terang dan baik terhadap suatu persoalan tertentu dan di dalam suatu daerah tertentu (Margono, 2005). Jadi, berdasarkan pendapat tersebut maka metode survei dalam penelitian ini adalah suatu cara kerja yang bertujuan untuk mencari informasi (data) dengan melakukan suatu penyelidikan kritis terhadap persoalan tertentu yang terjadi di dalam masyarakat, khususnya yang terjadi di sekolah (Wardani, 2014).

Di dalam penelitian bahasa, metode survei cendrung digunakan dalam penelitian deskriptif kualitatif. Menurut Nasution metode survei dapat digunakan dalam penelitian deskriptif (Nasution, 2006). Ini didukung oleh pendapat Singarimbun dan Effendi yang menyatakan bahwa metode survei dapat digunakan untuk maksud deskriptif, yaitu mengukur secara cermat terhadap fenomena sosial tertentu (Singarimbun \& Effendi, 1989).

Hal ini sejalan dengan pendapat Djadjasudarma kualitatif merupakan prosedur yang menghasilkan data deskriptif berupa data tertulis atau lisan di masyarakat bahasa (Djadjasudarma, 1993). Dengan demikian, dapatlah dipahami bahwa metode survei tidak bisa dilepaskan dari penelitian deskriptif kualitatif, terutama dalam mengumpulkan dan menggambarkan data secara alamiah (Ginting \& Situmorang, 2008).

Dengan menggunakan metode survei pada penelitian deskriptif kualitatif ini, diharapkan nantinya dapat memperoleh pemahaman yang mendalam mengenai kesalahan berbahasa pada siswa Kelas I SD (Sekolah Dasar) Negeri 89 Kota Bengkulu yang berbentuk kilir lidah (tongue slips) asembling (Setiawan, Muntaha, Sriati, \& Bintarti, 2014).

Adapun teknik pengumpulan data dalam penelitian ini dapat digambarkan sebagai berikut:

1. Teknik Simak

Teknik simak dapat disebut metode simak atau penyimakan, karena memang berupa penyimakan: dilakukan dengan menyimak, yaitu menyimak penggunaan bahasa (Moeliono \& Dardjowidjojo, 1988). Berdasarkan hal tersebut dapatlah dipahami bahwa teknik simak adalah teknik yang digunakan untuk menyimak penggunaan suatu bahasa (Sunarni, 2008).

Teknik simak dalam penelitian ini digunakan pada saat mengumpulkan data, dengan cara menyimak secara cermat pembicaraan siswa Kelas I SD (Sekolah Dasar) Negeri 89 Kota Bengkulu. Penyimakan dilakukan kerena tidak dimungkinkannya dilakukan perekaman, disebabkan pembicaraan oleh siswa Kelas I SD (Sekolah Dasar) Negeri 89 Kota Bengkulu berlangsung di lokasi yang tidak terduga, cukup ramai, dan luas. Sehingga, hal tersebut menimbulkan ketidaksiapan bagi penulis untuk merekam.

Penyimakan dilakukan terhadap pembicaraan siswa Kelas I SD (Sekolah Dasar) Negeri 89 Kota Bengkulu yang berlangsung di dalam kelas pada saat proses pembelajaran terjadi, dan di luar kelas pada saat siswa sedang bermain di waktu istirahat.

\section{Teknik Catat}

Menurut Sudaryanto teknik catat adalah teknik yang dilakukan dengan cara mencatat (Sudaryanto, 1990). Dalam melaksanakan teknik catat haruslah memperhatikan: a) tulisannya agar dibuat dengan cukup jelas, b) tidak lupa pula menyertakan kode-kode, c) perlu mempertimbangkan kualitas kertas agar catatan tidak mudah rusak, dan d) menggunakan warna tinta yang jelas (misalnya warna hitam).

Teknik catat dalam penelitian ini adalah mencatat semua data berupa kesalahan berbahasa dari pembicaraan siswa Kelas I SD (Sekolah Dasar) Negeri 89 Kota Bengkulu yang sesuai dengan tujuan penelitian. Pencatatan dilakukan setelah diperoleh data dari hasil penyimakan, atas pembicaraan yang mengandung kesalahan berbahasa (kilir lidah asembling) oleh siswa Kelas I SD (Sekolah Dasar) Negeri 89 Kota Bengkulu.

Lokasi penelitian dilakukan di SD (Sekolah Dasar) Negeri 89 Kelurahan Bentiring Kecamatan Muara Bangkahulu Kota Bengkulu. Pemilihan lokasi penelitian ini dikarenakan tempat tersebut dianggap sesuai dengan tujuan penelitian. 
Penelitian ini berlangsung dari tanggal 21 Maret 2009 dan berakhir pada tanggal 27 Maret 2009. Penelitian ini dilakukan secara berulang-ulang dengan tujuan adalah untuk mendapatkan suatu data yang lengkap, baik, dan juga tepat.

Mengenai sumber data, sumber data adalah asal peneliti memperoleh data yang dimaksud dan yang diinginkan(Sudaryanto, 1990). Jadi, sumber data dapat dipahami sebagai subyek asal darimana data dapat diperoleh peneliti sesuai dengan maksud dan keinginannya. Menurut Djadjasudarma validitas data kebahasaan dapat ditentukan melalui sumber data itu sendiri sesuai dengan kepentingan penelitian itu sendiri (Sudaryanto, 1990). Jadi, berdasarkan pandangan tersebut maka sumber data dalam penelitian ini adalah bahasa lisan yang digunakan oleh siswa Kelas I SD (Sekolah Dasar) Negeri 89 Kota Bengkulu saat berbicara.

Sementara data adalah bahan dasar atau bahan pertama yang nyata untuk menyusun seluruh pengetahuan (Sudaryanto, 1990). Menurut Margenau dan Bargamini data adalah fakta-fakta yang diolah oleh ilmu (Sudaryanto, 1990). Sedangkan menurut Sudaryanto data adalah bahan penelitian (Sudaryanto, 1990). Jadi, berdasarkan pandangan Sudaryanto dapatlah dipahami bahwa data sebenarnya adalah bahan dasar yang digunakan untuk penelitian. Berdasarkan pendapat tersebut maka data dalam penelitian ini ialah berupa bahasa lisan yang digunakan oleh siswa Kelas I SD (Sekolah Dasar) Negeri 89 Kota Bengkulu yang berbentuk kesalahan berbahasa (kilir lidah asembling).

Adapun teknik analisis data yang digunakan dalam penelitian ini dapat digambarkan sebagai berikut:

1. Transkripsi

Menurut Sudaryanto transkripsi merupakan bagian tahapan strategis dalam penelitian(Sudaryanto, 1990). Dengan tertulisnya dan tertatanya data secara sistematis dalam transkripsi tertentu dan pada kartu data tertentu merupakan wujud tahapan strategis (Sudaryanto, 1990). Jadi, berdasarkan pendapat tersebut transkripsi dalam penelitian ini adalah melakukan proses mentranskripsikan hasil penyimakan terhadap pembicaraan siswa Kelas I SD (Sekolah Dasar) Negeri 89 Kota Bengkulu yang mengandung kesalahan berbahasa (kilir lidah asembling), dari bentuk lisan ke dalam bentuk tulisan.

2. Identifikasi

Identifikasi merupakan cara kerja untuk menentukan ciri-ciri dari bahasa. Identifikasi dilakukan setelah didapat data tertulis dari proses mentranskripsikan hasil kegiatan berupa penyimakan. Dalam penelitian ini identifikasi digunakan untuk menemukan ciri-ciri dari kesalahan berbahasa, yang bertujuan untuk memperoleh suatu gambaran yang jelas tentang kegiatan berbicara siswa Kelas I SD (Sekolah Dasar) Negeri 89 Kota Bengkulu yang mengandung kesalahan, berupa kilir lidah (tongue slips) asembling. Ciri-ciri dari kesalahan berbahasa pada penelitian ini dapat diketahui melalui susunan huruf yang membentuk suatu kata.

3. Klasifikasi

Klasifikasi ialah penyusunan persoalan menurut golongannya (Sudaryanto, 1990). Berdasarkan pendapat tersebut, maka klasifikasi yang dilakukan dalam penelitian ini adalah mengelompokan kesalahan berbahasa ke dalam golongan kilir lidah (tongue slips) asembling.

4. Kesimpulan

Kesimpulan merupakan hasil akhir dari proses penganalisisan data. Kesimpulan dalam penelitian ini diperoleh dari suatu kajian mendalam terhadap pembicaraan siswa Kelas I SD (Sekolah Dasar) Negeri 89 Kota Bengkulu yang mengandung kesalahan, berupa kilir lidah (tongue slips) asembling, sehingga nantinya diperoleh suatu kesimpulan yang baik dan juga jelas.

\section{Hasil dan Pembahasan}

Berbicara adalah kegiatan yang tidak akan pernah terlepas dari kehidupan manusia. Hal ini disebabkan, karena secara lahiriah manusia itu merupakan makhluk sosial yang selalu terikat dengan kegiatan berinteraksi dan berkomunikasi. Agar mampu berbicara dengan baik, tentu saja seseorang haruslah melatih kemampuan bahasanya dengan baik pula. Dalam proses belajar-mengajar di sekolah, pada kenyataannya penguasaan terhadap kemampuan berbicara oleh anak didik (siswa) banyak sekali mendapat hambatan.

Hambatan dalam proses pengajaran keterampilan berbicara di sekolah tentu saja datang dari berbagai faktor, baik itu datang dari faktor eksternal, maupun datang dari faktor internal anak didik (siswa) itu sendiri. Hambatan yang sangat sering terjadi pada anak didik (siswa) pada saat berbicara dalam proses belajar-mengajar dan bersosialisasi dengan sesamanya ialah disebabkan oleh kekeliruan dalam berbicara. 
Dardjowidjojo beranggapan bahwa kekeliruan dalam berbicara dapat disebabkan oleh faktor kilir lidah(Dardjowidjojo, 2003). Kilir lidah adalah suatu fenomena dalam produksi ujaran di mana pembicara 'terkilir' lidahnya sehingga kata-kata yang diproduksi bukanlah kata yang dia maksudkan. Kekeliruan ini muncul, karena kita tidak memproduksi kata yang sebenarnya kita kehendaki. Di mana hal yang terjadi kita malah memproduksi kata lain, atau kita memindah-mindahkan bunyi, atau malah kita mengurutkan kata secara keliru.

Salah satu bentuk kekeliruan kilir lidah (tongue slips) yang akan penulis bahas dalam kesempatan ini adalah asembling. Asembling adalah bentuk kekeliruan di mana kata-kata yang dipilih sudah benar, tetapi asemblingnya keliru(Dardjowidjojo, 2003). Berikut ini akan dipaparkan hal-hal menarik atas data yang berasal dari siswa Kelas I SD (Sekolah Dasar) Negeri 89 Kota Bengkulu, yang dapat dideskripsikan sebagai berikut:

Data 1:
Guru
'Ini gambar apa anak-anak sekalian?'
Siswa
'Gambal keleleng buk. Keleleng buk Keleleng buk.'

Pada data 1 terdapat kekeliruan kilir lidah asembling, yaitu terjadinya perubahan dari kata [kelereng] menjadi [keleleng] dan kata [gambar] menjadi [gambal]. Hal ini dikarenakan adanya pergantian bunyi (huruf) dari /r/ menjadi /1/. Pada data 1 juga terdapat kata yang diucapkan secara keliru, yakni pada saat pengucapan kata [buk] yang seharusnya adalah [bu].

Data 2:
Guru
'Ibu membeli sirup. Coba ulangi!'
Siswa 'Ibu memberi cilup.'

Dalam data 2 kekeliruan kilir lidah asembling terjadi pada kata [membeli] yang menjadi [memberi] dan kata [sirup] menjadi [cilup]. Pada kata [membeli] yang berubah menjadi [memberi] kekeliruannya terjadi pada huruf /1/ yang berubah menjadi /r/, sedangkan pada kata [sirup] yang menjadi [cilup] kekeliruannya terjadi pada huruf /s/ yang berubah jadi huruf /c/ dan huruf /r/ yang berubah bentuk menjadi huruf /1/.

Data 3:
Siswa 1
'Ai, kau ko ngucak- ngucak olang ajo.'
Siswa 2
'Oi, gilo, gilo. Eh, eh, eh.'

Di data 3 terdapat kekeliruan kilir lidah asembling, yakni terjadinya perubahan dari kata [orang] menjadi [olang]. Hal ini dikarenakan adanya pergantian bunyi (huruf) dari /r/ menjadi /1/.

Data 4:
Siswa 1
'Ini mobil aku. Ini mobil aku.
Siswa 2
'Bukan, itu bobil ambo. Bobil ambo. Kau tu ambik- ambik bobil olang ajo.'

Pada data 4 kekeliruan kilir lidah asembling terjadi pada kata [mobil] yang berubah menjadi [bobil]. Hal ini dikarenakan adanya pergantian bunyi atau huruf dari $/ \mathrm{m} /$ menjadi $/ \mathrm{b} /$. Pada data 1 juga terdapat kata yang diucapkan secara keliru, yakni pada saat pengucapan kata [olang] yang mana seharusnya adalah diucapkan [orang].

Data 5:

Siswa $1 \quad$ Ah, ah, ah. Lambut kau lontok.

Siswa 2 Bukan rambut ambo eh. Rambut kau tulah.'

Di data 5 terdapat kekeliruan kilir lidah asembling, yaitu terjadinya perubahan dari kata [rambut] menjadi [lambut] dan [rontok] menjadi [lontok]. Perubahan tersebut dikarenakan adanya pergantian bunyi (huruf) dari huruf /r/ menjadi huruf /1/.

Data 6:

Siswa $1 \quad$ Parak kau botak. Parak botak. Parak botak.' 
Siswa 2

'Ngapo kau. Ambo lempal kek batu celak.'

Dalam data 6 kekeliruan kilir lidah asembling terjadi pada kata [palak] yang menjadi [parak], kata [lempar] menjadi [lempal], dan kata [kelak] menjadi [celak]. Pada kata [palak] yang berubah menjadi [parak] kekeliruannya terjadi pada huruf /1/ yang berubah menjadi /r/, pada kata [lempar] yang menjadi [lempal] kekeliruannya terjadi pada huruf $/ \mathrm{r} /$ yang berubah jadi huruf $/ 1 /$, sedangkan pada kata [kelak] menjadi [celak] perubahan terjadi pada huruf / $\mathrm{k} /$ yang menjadi huruf /c/.

Data 7:

Siswa 1 'Ibuk ambo pai ke ngumah-ngumah nak bagi- bagi kupon.'

Siswa $2 \quad$ Kupon apo. Kupon apo?'

Siswa $1 \quad$ Elum tau dia. Caleg lah masuk dak tau kau tu.'

Pada data 7 kekeliruan kilir lidah asembling terjadi pada kata [rumah-rumah] yang berubah menjadi [ngumah-ngumah]. Hal ini dikarenakan adanya pergantian bunyi atau huruf dari /r/ menjadi /ng/ atau $/ \mathrm{y} /$. Pada data 7 juga terdapat kata yang diucapkan secara keliru, yakni pada saat pengucapan kata [ibuk] yang mana seharusnya ialah diucapkan [ibu] dan kata [elum] yang sebenarnya adalah [belum].

Data 8:

Siswa $1 \quad$ 'Pintak oi, bagi oi. Pelit nian kau tu dak.'

Siswa $2 \quad$ 'Beli yak coy. Olang cuma sedikit?'

Di data 8 terdapat kekeliruan kilir lidah asembling, yaitu terjadinya perubahan dari kata [minta] menjadi [pintak] dan kata [orang] menjadi [olang]. Pada kata [minta] yang berubah menjadi [pintak] kekeliruannya terjadi pada huruf $/ \mathrm{m} /$ yang berubah menjadi $/ \mathrm{p} /$, dan pada kata [pintak] juga terjadi penambahan huruf yang seharusnya tidak ada, yaitu $/ \mathrm{k} /$. Sedangkan pada kata [orang] yang menjadi [olang] kekeliruannya terjadi pada huruf /r/ yang berubah jadi huruf /1/.

Data 9:

Siswa $1 \quad$ 'Ambo takut ke ayam. Kau cak mano?.'

Siswa 2 'Kalo ambo guyai ayam, eh, eh. Kau idak eh.'

Siswa 1 'Ambo gulai kacang, gulai telung, telung melah.'

Pada data 9 kekeliruan kilir lidah asembling terjadi pada kata [gulai] yang berubah menjadi [guyai], kata [terung] yang menjadi [telung], dan kata [merah] yang menjadi [melah]. Hal ini dikarenakan adanya pergantian bunyi atau huruf dari /1/ menjadi /y/ dan /r/ menjadi /l/.

Data 10:

Siswa $1 \quad$ 'Ayam ambo yang namonyo tabul takut'

Siswa 2 'Io, datal cengeng.'

Siswa 1 'Namonyo ayam belatabis.'

Di data 10 terdapat kekeliruan kilir lidah asembling, yaitu terjadinya perubahan dari kata [dasar] menjadi [datal] dan kata [telatabis] menjadi [belatabis]. Pada kata [dasar] yang berubah menjadi [datal] kekeliruannya terjadi pada huruf $/ \mathrm{s} / \mathrm{dan} / \mathrm{r} /$ yang berubah menjadi /t/ dan $/ 1 /$. Sedangkan pada kata [telatabis] yang menjadi [belatabis] kekeliruannya terjadi pada huruf /t/ yang berubah jadi huruf $/ \mathrm{b} /$.

Data 11:

Siswa 1

Siswa 2

Siswa 1
'Ambo ndak tengok. Pasti ayamnyo tu beli di tabut.'

'Jangan pegang! Bisa nyotok nyo tu ?'

'Kalo bisa cotok aku, eh eh. Betet sekali mati betet iko ko.'

Dalam data 11 kekeliruan kilir lidah asembling terjadi pada kata [tabot] yang menjadi [tabut] dan kata [petet] menjadi [betet]. Pada kata [tabot] yang berubah menjadi [tabut] kekeliruannya terjadi pada huruf /o/ yang berubah menjadi / $\mathrm{u}$, sedangkan pada kata [petet] yang menjadi [betet] perubahan terjadi pada huruf /p/ yang menjadi huruf /b/.

Data 12:

Siswa 1 'Ambo pacak makan daun yang tajam. Ambo makan 


$\begin{array}{lc}\text { langsung teguk-teguk.' } \\ \text { Siswa } 2 & \text { 'Makan selop ko. Bisa dak ?' } \\ \text { Siswa } 1 & \text { 'Cicing olang gilo.' }\end{array}$

Pada data 12 kekeliruan kilir lidah asembling terjadi pada kata [orang] yang berubah menjadi [olang]. Hal ini dikarenakan adanya pergantian bunyi atau huruf dari /r/ menjadi /1/.

Data 13:
Siswa 1
'Melawan dak dekek ambo?.'
Siswa 2
'Kasih kentut baye supayo nyo mabuk.'
Siswa 1
'Kasih ludah keyak kau tu.'

Di data 13 terdapat kekeliruan kilir lidah asembling, yaitu terjadinya perubahan dari kata [kelak] menjadi [kayak], di mana kekeliruannya terjadi pada huruf /1/ yang berubah menjadi /y/.

Data 14:
Siswa 1
'Ambo dak lajoi ayam yang tabut eh. Ayam ambo.'
Siswa 2
'Tengok eh, lagoi ayam. Nak nonton ambo.'

Pada data 14 kekeliruan kilir lidah asembling terjadi pada kata [lagoi] yang berubah menjadi [lajoi]. Hal ini dikarenakan adanya pergantian bunyi atau huruf dari /g/ menjadi /j/. Pada data 14 juga terdapat kata yang diucapkan secara keliru, yakni pada saat pengucapan kata [dak] yang mana seharusnya ialah diucapkan [ndak].

Data 15:
Siswa 1
'Ayam mano lagokan keyak yo. Ndak lagokan di luar ko'
Siswa 2
'Ado bebek, lawan itu.'
Siswa 1
'Mano suai, tengok!.'

Dalam data 15 kekeliruan kilir lidah asembling terjadi pada kata [kalak] yang menjadi [keyak]. Pada kata [kalak] yang berubah menjadi [keyak] kekeliruannya terjadi pada huruf /1/ yang berubah menjadi /y/.

Data 16:

Siswa $1 \quad$ 'Ambo ndak belanjo neh. Belanjo, belanji kelupuk.'

Siswa 2 'Biallah, ambo jugo ado duit neh.'

Pada data 16 kekeliruan kilir lidah asembling terjadi pada kata [kerupuk] yang berubah menjadi [kelupuk] dan kata [biarlah] menjadi [biallah]. Hal ini dikarenakan adanya pergantian bunyi atau huruf dari /r/ menjadi /1/.

Data 17:

Siswa $1 \quad$ 'Keleleng, keleleng. Ambo ado keleleng.'

Siswa 2 'Neh, ambo jugo ado.'

Di data 17 terdapat kekeliruan kilir lidah asembling, yaitu terjadinya perubahan dari kata [kelereng] menjadi [keleleng]. Pada kata [kelereng] yang berubah menjadi [keleleng] kekeliruannya terjadi pada huruf /r/ yang berubah menjadi /1/.

Data 18:
Siswa 1
'Oi, ndak keloik dak kau tu.'
Siswa 2
'Bagi oi. Bagi oi. Ambo ndak.'

Pada data 18 kekeliruan kilir lidah asembling terjadi pada kata [keripik] yang berubah menjadi [kelipik]. Hal ini dikarenakan adanya pergantian bunyi atau huruf dari /r/ menjadi /1/.

Data 19:

Siswa $1 \quad$ 'Ayuk Ambo cekolah, nyo tu pai tadi.' 
Siswa 2

'Ambo jugo, ayuk ambo jugo.'

Dalam data 19 kekeliruan kilir lidah asembling terjadi pada kata [sekolah] yang menjadi [cekolah]. Pada kata [sekolah] yang berubah menjadi [cekolah] kekeliruannya terjadi pada huruf /s/ yang berubah menjadi /c/.

Data 20:

Siswa 1 'Ambo makan pisang. Ambo makan pisang. Cau idak'

Siswa 2 'Biarlah.'

Di data 20 terdapat kekeliruan kilir lidah asembling, yaitu terjadinya perubahan dari kata [kau] menjadi [cau]. Pada kata [kau] yang berubah menjadi [cau] kekeliruannya terjadi pada huruf $/ \mathrm{k} / \mathrm{yang}$ berubah menjadi /c/.

Data 21:

Siswa $1 \quad$ Oi, jangan kucak olang. Kelak ambo tinju kau.'

Siswa 2 'Idak ado. Idak ado eh, ambo kucak kau.'

Pada data 21 kekeliruan kilir lidah asembling terjadi pada kata [orang] yang berubah menjadi [olang]. Hal ini dikarenakan adanya pergantian bunyi atau huruf dari /r/ menjadi /1/.

Berdasarkan penjelasan yang ada dapatlah dilihat bahwa kilir lidah (tongue slips) asembling yang dialami oleh siswa Kelas I SD (Sekolah Dasar) Negeri 89 Kota Bengkulu, pada umumnya terjadi pada huruf-huruf berikut ini, yaitu: huruf /r/ yang berubah menjadi /1/, huruf /s/ yang berubah jadi huruf /c/, huruf /1/ yang berubah menjadi / $/$, huruf /m/ yang berubah menjadi /b/, huruf / $/$ / yang berubah jadi huruf /c/, huruf /r/ yang berubah menjadi /ng/ atau /g/, huruf /m/ yang berubah menjadi /p/, huruf /1/ yang berubah menjadi /y/, huruf /p/ yang berubah menjadi huruf /b/, huruf /o/ yang berubah menjadi /u/, dan huruf /g/ yang berubah menjadi /j/.

Siswa Kelas I SD (Sekolah Dasar) Negeri 89 Kota Bengkulu juga mengalami masalah dalam pengucapan kata, di mana kata yang diucapkan sering sekali salah, hal ini seperti dalam pengucapan kata [ibuk] yang mana seharusnya ialah diucapkan [ibu], pengucapan kata [elum] yang sebenarnya adalah [belum], dan pengucapan kata [dak] yang mana seharusnya ialah diucapkan [ndak]. Berdasarkan penjelasan yang ada, maka dapatlah diketahui bahwa penyebab kekeliruan kilir lidah asembling yang dialami oleh siswa Kelas I SD (Sekolah Dasar) Negeri 89 Kota Bengkulu, antara lain adalah belum sempurna atau terdapatnya kerusakan pada alat-alat bicara yang dimiliki siswa, pikiran siswa belum memiliki gambaran yang baik tentang kosa kata, dan adanya pengaruh bahasa daerah terhadap penguasaan bahasa Indonesia.

\section{Kesimpulan}

Berdasarkan penelitian yang penulis lakukan, maka dapatlah diketahui bahwa kekeliruan kilir lidah (tongue slips) asembling yang dialami oleh siswa Kelas I SD (Sekolah Dasar) Negeri 89 Kota Bengkulu, pada umumnya terjadi pada huruf-huruf konsonan, seperti :

1. Huruf $/ \mathrm{r} /$ yang berubah menjadi $/ 1 /$.

2. Huruf /s/ yang berubah jadi huruf /c/.

3. Huruf $/ 1 /$ yang berubah menjadi /r/.

4. Huruf $/ \mathrm{m} /$ yang berubah menjadi $/ \mathrm{b} /$.

5. Huruf $/ \mathrm{k} /$ yang berubah jadi huruf $/ \mathrm{c} /$.

6. Huruf $/ \mathrm{r} /$ yang berubah menjadi /ng/ atau / $\mathrm{g} /$.

7. Huruf $/ \mathrm{m} /$ yang berubah menjadi $/ \mathrm{p} /$.

8. Huruf /1/ yang berubah menjadi /y/.

9. Huruf /p/ yang berubah menjadi huruf /b/.

10. Huruf /o/ yang berubah menjadi /u/

11. Huruf /g/ yang berubah menjadi /j/.

Penelitian ini juga memperlihatkan bahwa Siswa Kelas I SD (Sekolah Dasar) Negeri 89 Kota Bengkulu juga mengalami masalah dalam pengucapan kata. Di mana kata yang diucapkan sering sekali mengalami kesalahan dan kekeliruan. Hal ini dapat dilihat dari kata yang diucapkan siswa, seperti:

1. Pengucapan kata [ibuk] yang mana seharusnya ialah diucapkan [ibu]. 
2. Pengucapan kata [elum] yang sebenarnya adalah diucapkan [belum].

3. Pengucapan kata [dak] yang mana seharusnya ialah diucapkan [ndak].

Berdasarkan penjelasan yang ada maka dapatlah diketahui bahwa penyebab kekeliruan kilir lidah (tongue slips) asembling yang dialami oleh siswa Kelas I SD (Sekolah Dasar) Negeri 89 Kota Bengkulu, adalah sebagai berikut:

1. Belum sempurna atau terdapatnya kerusakan pada alat-alat bicara yang dimiliki siswa Kelas I SD (Sekolah Dasar) Negeri 89 Kota Bengkulu.

2. Dalam pikiran siswa Kelas I SD (Sekolah Dasar) Negeri 89 Kota Bengkulu belum memiliki gambaran tentang kosa kata yang baik.

3. Adanya pengaruh bahasa daerah terhadap penguasaan bahasa Indonesia.

Penulis mengharapkan agar para pendidik (guru) dapat memberikan latihan secara terus-menerus terhadap kemampuan berbahasa siswa. Hal ini dilakukan adalah untuk membina dan memperbaiki kemampuan berbahasa siswa yang terdiri atas empat aspek, yaitu menyimak, berbicara, membaca, dan menulis. Latihan kemampuan berbahasa yang diberikan oleh guru terhadap siswa, bukan saja dapat meningkatkan kemampuan berbahasa siswa, tetapi hal lainnya adalah tentu saja merupakan salah satu cara mengatasi masalah berbahasa yang dialami siswa seperti masalah kekeliruan berbahasa (bicara) berupa kilir lidah (tongue slips) asembling.

\section{Referensi}

Andari, N. (2013). Kalimat yang Diproduksi oleh Mahasiswa Pascasarjana UNESA Ketika Memaparkan Makalah. Diglossia: Jurnal Kajian Ilmiah Kebahasaan Dan Kesusastraan, 4(2).

Andra, V. (2018). Kilir Lidah Gangguan Bahasa Anak. Tarbawy: Jurnal Pendidikan Islam, 5(1), 123-134.

Dardjowidjojo, S. (2003). Psikolinguistik: Pengantar pemahaman bahasa manusia. Yayasan Pustaka Obor Indonesia.

Djadjasudarma, T. F. (1993). Metode linguistik: Ancangan metode penelitian dan kajian. Eresco.

Ginting, P., \& Situmorang, S. H. (2008). Filsafat Ilmu dan Metode Riset. Terbitan Pertaman. Medan USUPress.

Gunarti, W., \& Muis, A. (2014). Metode Pengembangan Perilaku dan Kemampuan Dasar AUD.

Margono, S. (2005). Metodologi Penelitian Pendidikan, Cet. V Jakarta: Rineka Cipta.

Moeliono, A. M., \& Dardjowidjojo, S. (1988). Tata bahasa baku bahasa Indonesia. Departemen Pendidikan dan Kebudayaan, Republik Indonesia.

Mulyati, Y. (2015). Keterampilan Berbahasa Indonesia SD.

Nasution, S. (2006). Metode Research (Penelitian Ilmiah), cet. Ke-8, Jakarta: PT Bumi Aksara.

Sanjaya, W. (2015). Perencanaan dan desain sistem pembelajaran. Bogor: Kencana.

Sari, I. R. (2014). Analisis Pragmatik Pelanggaran Tindak Tutur Guru Di SMA Lentera. Pena: Jurnal Pendidikan Bahasa Dan Sastra, 3(2).

Setiawan, B., Muntaha, A., Sriati, A., \& Bintarti, A. (2014). Metode Penelitian Komunikasi.

Singarimbun, M., \& Effendi, S. (1989). Metodologi penelitian survei. Jakarta: LP3ES.

Sudaryanto. (1990). Aneka konsep kedataan lingual dalam linguistik. Duta Wacana University Press.

Sumantri, M. (2014). Perkembangan peserta didik.

Sunarni, N. (2008). Drama Sebuah Alternatif Objek Penelitian Bahasa. Jurnal Sastra Jepang, 8(1), 61-69.

Wardani, I. (2014). Penelitian tindakan kelas. 